\title{
Clare Gerada: Mindfulness is useful but not the only option
}

\author{
Clare Gerada GP partner
}

Hurley Group, London, UK

\begin{abstract}
Mindfulness has recently been heavily promoted as a solution to the high levels of burnout and mental distress seen among doctors. It has become something of a one-size-fits-all response to a host of modern problems - designed to fit easily into anyone's life regardless of their background, beliefs, or values.

The reported benefits are broad. They include stress reduction, reduced rumination, decreased negative affect (as in depression and anxiety), less emotional reactivity or more effective regulation of emotion, and increased focus. It's an impressive list, when you consider its origins as a meditative activity and how simple it can be: closing one's eyes, deep breathing, and paying intense attention to what's happening in the present moment in the mind, body, and external environment.
\end{abstract}

As with many self help interventions, mindfulness largely preaches to the converted. Those who choose to engage in it are, naturally, people who find this method acceptable. A recent feasibility study on the use of mindfulness in foundation year doctors used a self selected group (20 in total) who then went on to attend a six week course on "Mindfulness in the Workplace," where self reported measures were taken immediately before the course and after its completion. The before and after outcomes showed a modest improvement, although it's telling that only $35 \%$ of participants completed the full intervention - the main barrier being work commitments. ${ }^{1}$

This is not to say that mindfulness isn't beneficial. Increasing evidence shows that it does have positive outcomes in different areas and different modalities: for example, mindfulness based cognitive therapy has been shown to be efficacious in a range of physical and mental health conditions. ${ }^{23}$ However, regarding doctors and their role in preventing mental health problems, there is a danger of mindfulness becoming a panacea. This could risk allowing people in authority to tick a box, devolving themselves of responsibility for making the workplace-the source of most stress-a safer environment. Moreover, most interventions will show improvement at the six week mark, from swimming with dolphins to a course of psychological therapy. What is important is for doctors to find their own sustaining solutions for destressing at the end of a busy day or between difficult consultations (so called "housekeeping").

Each of us needs to understand the limits of what we can do and should take steps to maintain our psychological equilibrium. I find that watching back-to-back episodes of Come Dine with $M e$ or engaging in my secret passion of building Lego models helps me to empty my brain of the day's worries. Mindfulness is just one intervention among many.

Competing interests: See www.bmj.com/about-bmj/freelance-contributors. Provenance and peer review: Commissioned; not externally peer reviewed.

1 Bu CNN, Cotzias E, Panagioti M. Mindfulness intervention for foundation year doctors: a feasibility study. Pilot Feasibility Stud 2019;5:61. 10.1186/s40814-019-0449-y. 31061716 UK Mindfulness All-Party Parliamentary Group. Mindful nation UK report. Oct 2015. https: //www.themindfulnessinitiative.org/mindful-nation-report.

3 Piet J, Hougaard $E$. The effect of mindfulness-based cognitive therapy for prevention of relapse in recurrent major depressive disorder: a systematic review and meta-analysis. Clin Psychol Rev 2011;31:1032-40. 10.1016/j.cpr.2011.05.002 21802618

Published by the BMJ Publishing Group Limited. For permission to use (where not already granted under a licence) please go to http://group.bmj.com/group/rights-licensing/ permissions 